\title{
Utilization of Google Drive in Improving the Effectiveness of Self-Regulated Learning (SRL) Management
}

(A Case Study of $6^{\text {th }}$ Semester Students in Educational Innovation Course, English Education Program, Universitas Singaperbangsa Karawang Academic Year 2018)

\author{
${ }^{1 \text { st }}$ Maman Suryaman, \\ English Education Program- \\ UNSIKA \\ maman.suryaman@fkip.unsika.ac.id
}

\author{
${ }^{2 n d}$ Kriswanda Krishnapatria \\ English Education Program- \\ UNSIKA \\ kriswanda.krishnapatria@staff.unsika.ac.id,
}

\author{
${ }^{3 r d}$ Arip Solehudin \\ Informatics Engineering Program- \\ UNSIKA \\ arip.solehudin@gmail.com
}

\begin{abstract}
This research focuses on measuring the contribution of famousGoogle Drive (G-Drive) application in enhancing the effectiveness of students' Self-Regulated Learning (SRL). Learning effectiveness is largely determined by several factors such as supportive classroom climate, learning opportunity, curricular alignment, learning orientation establishment, coherent content, thoughtful discourse, practice and application activities, scaffolding students' task engagement, strategy teaching, co-operative learning, goal-oriented assessment, and achievement expectations. In addition, information and communication technology is very helpful in exploring the world with unlimited resources (empowerment), providing the right choice of devices, giving space to work together in real-time (team work), and being affordable as well as easy managed (scalability). This study used qualitative approach to depict or describe the general overview of the use of $G$-Drive in learning process and the effectiveness of independent learning. This isa case study researchbased on an in-depth investigation of a single individual, group or event to explore the causes of underlying principles. The results show that $G$ Drivehas provided benefits to learning management in the forms of following aspects: learning management, teaching materials, self-assessment, learning development tools, communication tools, completeness and management tools of students. In conclusion, learning with $G$-Driveresulted on active learning, more authentic activities, developed students' metacognition, fostered intrinsic motivation, and improved students' responsibility.
\end{abstract}

Keywords: effectiveness of learning management, Google Drive, self-regulated learning

\section{INTRODUCTION}

The management of education and learning from day to day continues to improve in accordance with the demands of the needs, developments and dynamics of the advancement of science-technology. Perhaps we already know the administration of learning that has been carried out by teachers, both primary and secondary school teachers, and lecturers in higher education. In general, they do the tasks by administering them in writing in books or other papers. The development of information and communication technology with computer aids has changed many ways in life, including education and more specifically learning administration. Learning, like other disciplines, also experience very rapid development in terms of concept and practice. The learning activities that were originally centered on the teacher had shifted to the center of students (student centered learning). Likewise, teaching materials, which were originally in the form of printed books, have now turned into digital one. Similarly, in the assessment what was originally the domination of teachers (teachers and lecturers) has now begun to shift to self-assessment, peer assessment and teacher assessment. All of those activities must be well administered, thus demonstrating a learning governance that has good accountability. For this reason, a method, a tool that has the reliability, speed, and accuracy is required, so that it can get results according to circumstances.

Information and communication technology (ICT) has presented a completely new learning environment for students, thus requiring different skills to succeed. When looking at the current distribution and use of ICT in modern society, especially by the younger generation called digital generation, it is crystal clear that ICT will influence the complete learning process today and in the future. Authenticity is an important issue that must be considered in the design and development of a learning environment (Collins, 1996). The learning environment needs to reflect the potential use of knowledge that students should learn, to prevent knowledge gained from being inert (Bransford, Sherwood, Hasselbring, Kinzer, \& Williams, 1990; Duffy \& Knuth, 1990). In addition, teachers must stimulate students to be involved in the construction of active knowledge. This requires an open learning environment rather than learning the environment that focuses on mere fact transmission (Collins, 1996; Hannafin, Hall, Land, \& Hill, 1994; Jonassen, Peck, \& Wilson, 1999). 
Another aspect that certainly affects the use of ICTs is access to technology (Kennewell, Parkinson, \& Tanner, 2000; OTA, 1995). This refers not only to the number of computers, but also to the placement of equipment, for example in the classroom or in the computer laboratory. Kennewell et al. (2000) find it very important that computers are placed in class, to maximize the opportunities for curriculum activities. The ICT environment enhances the experience of students and teachers and utilizes intensive learning time to get better results. The ICT environment has been developed using different software and also an expanded experience in developing web and multimedia-based materials. In other words, ICTs have an important role in changing and modernizing the education system and ways of learning.

Currently, the Google application provides various alternatives in answering various practical needs and problems in human life. One of the popular applications is Google Drive, where the benefits obtained by using google drive include: (1) unlimited storage space can be used by Drive, Gmail, and Google Photos; (2) Photos, videos, presentations, PDFs - even Microsoft Office files, whatever the file type, can all be stored safely on Drive; (3) Drive files are private, and can be shared, can invite others to quickly see, comment, and edit selected files or folders, online collaboration that makes things easier; (4) File security on Drive will remain safe, whatever happens with one's smartphone, tablet or computer, the Drive is encrypted using SSL, the same security protocol that is used in Gmail and other Google services; (5) being able to access through a smartphone or computer. Thus, by utilizing Google Drive in the management of student centered learning, there are many conveniences that support the improvement of learning effectiveness.

\section{Literature Review}

Anderson, 1991 (in Scheerens, 2004) argues that the primary component that builds learning effectiveness consists of four parts, namely: the enacted curriculum, classroom environment and climate, actual teaching activities and stimulation involvement. Furthermore, Wang and Walberg, 2001 (in Scheerens, 2004: 44-45) proposed 12 principles of effective teaching, including: supportive classroom climate, opportunity to learn, curricular alignment, establishing learning orientation, content that is coherent or easily understood (coherent content), deep learning (thoughtful discourse), practice and application activities, involvement of students' scaffolding tasks, engagement strategies, strategy teaching, co-operative learning, goal-oriented assessments and achievement expectations.

Teacher should provide whatever assistance students need to enable them to engage in productive learning activities. Arrangement and support can be reduced along with the development of students' abilities. Applying a teaching model that directs students into independent learning strategies and settings would give birth to meta-cognitive awareness and self-regulation. In the context of searching knowledge, it is echoed in learning problem solving and learning skills. Furthermore, students often benefit from working together or small groups to build understanding or help each other in mastering plenary teaching materials. The teacher uses a variety of formal and informal assessment methods to monitor the progress of achieving learning objectives. Assessment is carried out thoroughly covering the ability of students in reasoning and problem solving processes. The teacher then perfects and monitors the suitability of progress in achieving the expected learning outcomes.

\section{The Role of Information Communication Technology (ICT) in Education and Learning}

Research shows that most teachers do not utilize the potential of ICTs to contribute to the quality of learning environment even though they consider this potential to be significant (Smeets, 2005). Harris (2002) conducted a case study at three elementary schools and three secondary schools, which focused on innovative pedagogical practices involving ICT. Harris (2002) concludes that the benefits of ICT will be obtained "... when confident teachers are willing to explore new opportunities to change their classroom practices using ICT." As a consequence, the use of ICTs will not only improve the learning environment but also prepare future generations for better life and future careers (Wheeler, 2001). Changes in teacher pools will change into responsibilities and skills for future teaching involving high-level ICTs and the need to facilitate more than didactic teaching roles (Littlejohn et al., 2002).

ICT can improve the quality of education in several ways: by increasing learning motivation and involvement, by facilitating the acquisition of basic skills, and by improving teacher training. ICT is also a transformational tool which, if used properly, can drive a shift to a student-centered environment. ICTs, especially computers and Internet technology, enable new ways of teaching and learning, not only allowing teachers and students to do what they have done before in a better way, but also affecting what students have to learn and playing an important role in how students should learn. As the curriculum shifts from "content-centered" to "competencybased", the way the curriculum is delivered now shifts from "teacher-centered" learning to "student-centered" learning. ICT provides could also motivate students to learn by providing videos, television and multimedia computer software that combines text, sound, and colored moving images that can be used to provide challenging and authentic content that will involve students in the learning process.

ICT increases the flexibility of delivering knowledge and education, so students can access them anytime and anywhere. This can affect the way students are taught and how they learn because now the process is driven by students and not by teachers. This in turn will better prepare students for lifelong learning as well as to improve the quality of learning. With geographical 
flexibility, technology-facilitated education programs also eliminate many temporal constraints faced by students with special needs (Moore \&Kearsley, 1996). As a result, students begin to appreciate the ability to study anywhere, anytime and anywhere. One of the most vital ICT contributions in education is-Easy Access to Learning. With the help of ICT, students can now browse through ebooks, sample exam papers, previous year papers, and also have easy access to resource persons (facilitator), mentors, experts, researchers, professionals, and colleagues - all over the world. This flexibility has increased the availability of just-in-time learning and provided learning opportunities for more students who were previously limited by other commitments (Young, 2002).

\section{METHODS}

This study uses a descriptive qualitative approach to describe the effectiveness of $G$-Drive support in managing self-regulated learning in the form of words or narratives. This research type is a case study, in the form of intensive testing of a single entity that is equipped with sources and evidence of objects and subjects observed and limited to space and time. Case studies as part of qualitative research recognize that social reality is a sociohistorical construction and is therefore subjective. While the purpose of qualitative research is to understand and describe the typical complexity (idiosyncratic nature) of a phenomenon. Therefore, qualitative research is more suitable to use non-positivistic paradigms such as interpretive, critical, or postmodern paradigms (Aditomo, 2014). Cuban et al. (2001) assume that the triangulation process is carried out through data from various sources and forms (interviews, observations, and surveys); by conducting this process qualitative researchers can state that the results of their research are "objective" (Aditomo, 2014). Researchers can use several techniques in data collection, such as in-depth interviews and questionnaires. Several stages in making a case study begin with determining the problem, making designs and instruments, collecting data, making data analysis, and preparing research reports. The end result of the case study is a deep understanding of a phenomenon (Yona, 2006).

The steps in conducting case study research are: (1) Analyzing in depth the cases and situations that are the subject of research; (2) trying to understand the case based on the point of view of the person who used to run (if in the form of activity) or who experienced it; (3) recording the interrelationships between events and analyzing the factors that cause them to be interrelated. This study uses a case study design with a view to understanding the phenomenon of what is experienced by the subject of the study which in this case is the advantage of using $G$-Drive in learning and the impact that occurs on self-regulated learning.

The research was conducted in English Education Study Program, Faculty of Teacher Training and
Education, UniversitasSingaperbangsaKarawang. This location was chosen because it met the criteria including: a) it is an institution that organizes learning and learning processes; b) it allows for the use of $G$-Drive in the independent learning process. Furthermore, subjects in this study were students in the sixth semester of academic year 2017-2018. The research subjects were determined using a purposive sampling technique. Purposive technique is a technique in which the determination of the subject or research sample is adjusted to the purpose of the research and is based on certain criteria that have been established. The criteria of the students who are the subjects in this study are: (1) registered as sixth semester students, (2) taking Educational Innovation courses, (3) being able to use the internet and G-Drive application.

The data in this study consisted of two data sources, namely primary data and secondary data. The purpose of the primary data is data obtained directly from the subject as the source of information sought. The primary data in this study are students. The source in the form of primary data is used to obtain data about students' views about self-regulated learning. While secondary sources are from leaders, lecturers, and staff who interact directly with students.

The data collection techniques are carried out in two ways, namely documentation and questionnaire. Firstly, documentation technique is carried out by tracing or tracking data from documents or something that has historical value, where the data traced is related to the research theme. In documentation researchers used it to obtain information regarding: (1) planning $G$-Drive interface display format design, (2) the types of documents prepared and used in learning; (3) operating system from $G$-Drive; (4) technology and equipment used in operating the system. Secondly, questionnaire is a method of data collection by distributing questionnaires consisting of a number of questions to be answered by respondents. Questionnaires must represent research questions and are related to research proposals. Therefore, the questionnaire must be arranged in a clear and easy to understand so that it will facilitate the respondent to read and understand the purpose of each question in it. On this occasion, the questionnaire was intended to reveal the condition of self-learning that occurred. For this reason, questionnaires were given to students through an online questionnaire system through $G$-Drive.

\section{RESULTS AND DISCUSSION}

\section{A. Research Result}

$G$-Drive construction in learning process includes several things including: appearance format, accessibility and operating system.

1. Appearance Format:

- Folder Learning Guide consists of: lecture organization, material summary, self and peer assessment guidelines, guidelines for writing assignments and scientific papers, 
source cards and learning motivation video; in addition, English Language books, research sources books, Educational Innovation resources books are all in digital form.

- Task Folder for individuals and groups: this folder contains tasks created by students both individually and in groups, in one small group consisting of 3-5 people. Group members can give and receive individual assignment files for the benefit of the whole group assignments and peer assessment. If the file has been entered into a folder, then it cannot be deleted by anyone except by the lecturer or admin.

- Form Folders for individual and group task

- Form Folders for individual assessment

- Form Folder for group assessment

- Form Folder for Presentation assessment

- Task Recording Folder in the form of worksheets consisting of: individual assignments, group assignments, presentation assignments, self-assessment assignments, peer assessment assignments and presentation assessment assignments.

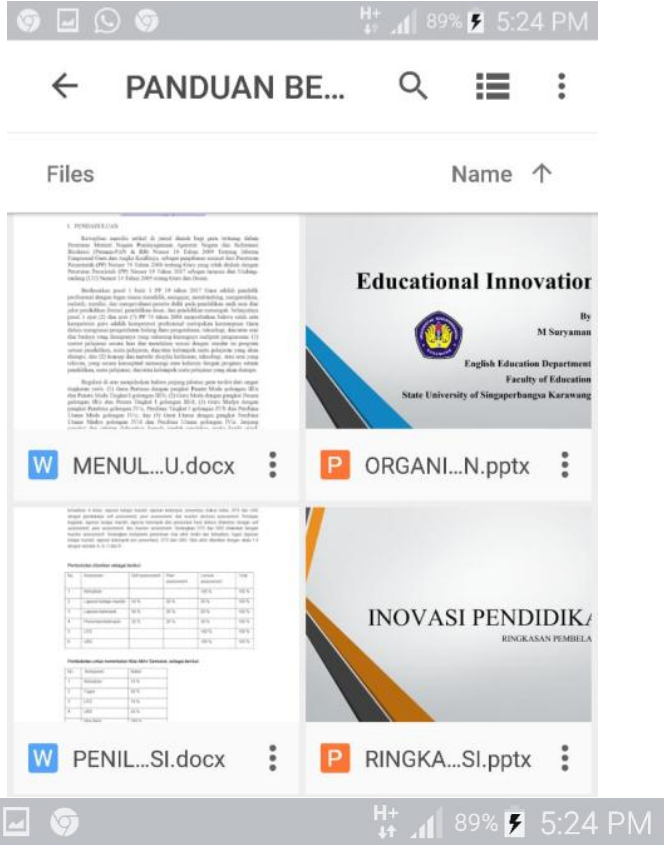

\section{$\leftarrow$ INOVASI PEN... Q $\#$ :}

Folders Name 个

\begin{tabular}{|l|l|l|}
\hline E-BOOK & $\vdots$ & $\begin{array}{l}\text { E-BOOK } \\
\text { INNOVASI }\end{array}$ \\
ENGLISH & $\vdots$ & \\
E-BOOK \\
RESEARCH
\end{tabular}

Figure 1. Contents of Educational Innovation course files and folders in the $G$-Drive

2. Accessibility:

- All folders can be accessed by students, except that the result folder can only be seen.

- All instructional materials and study guidelines are available in the study guide folder and source books; besides, there are also material summary files based on discussion topics.

- All applications of tasks created by students can be stored and accessed in the task folder according to their type.

- Teachers can monitor every time the development of the implementation of tasks by students. 
- Each student can monitor the level of learning progress based on the results of self-, peers and lecturers' assessment.

- Students and lecturers can access whenever and wherever the system by using compatible equipment, such as PCs, laptops, tablets or cellphones.

3. Operating System:

- It is easy and simple, as if we stored and retrieved files from cabinets manually with lockers that are named after each locker.

- Everything is softcopy, so no need to print anything. As a result, it saves costs for printing assignments and learning administration formats.

- It has a large capacity, so that any application can be stored and recovered.

- Being able to involve students with each other, and also between students and lecturers.

- Being able to send emails, forums, chat, and do teleconferences.

- It can be accessed anywhere because it is stored in cloud system, so it is mobile.

- Security is regulated based on the access rights provided by the lecturer or admin in the shared folders and files.

\section{Learning Conditions}

Based on the questionnaire given to students, the impact occurred on learning as follows:

a. First of all, as many as $94,64 \%$ of students stated that engaging respondents with $G$-Drive has made active learning, which is marked by:

- The learning situation has provided more learning experiences to achieve learning goals $(96,43 \%)$,

- Learning using peer teaching techniques to increase the participation of all students in the class $(92,86 \%)$,

- The learning situation has required students to create the framework needed to motivate challenging work $(89,29 \%)$, and

- The learning has built up the habit of gaining new knowledge, not just merely knowing $(100 \%)$.

b. Next, as many as $90,48 \%$ of students stated that the learning had made activities more authentic, indicated by:

- Designing imitation sessions or role playing activities based on real life situations $(91,07 \%)$,

- Encouraging students to use real-world resources from the open web $(92,86 \%)$,

- Creating assessment models that develop actual responsibilities $(87,5 \%)$. c. As many as $91,96 \%$ of students stated that the learning had developed students' metacognition, indicated by:

- Encouraging students to evaluate themselves regarding what they know and do not know (100\%),

- Giving students opportunities for selfreflection using activity journals (daily notes) or joint activity notes $(83,93 \%)$,

- Explaining how experts approach problems, including mental steps that are hidden $(89,29 \%)$,

- Using digital tools that provide easy access $(94,64 \%)$.

d. A total of $91,07 \%$ of students stated that learning has fostered intrinsic motivation, which is indicated by:

- Accelerating the growth of mindset through learning completeness, as a step to success $(87,5 \%)$,

- Encouraging students to make their own learning goals, and record their progress towards the goals they want to achieve $(89,29 \%)$,

- Introducing cooperative and collaborative activities that make common goals $(96,43 \%)$.

e. A total of $96,88 \%$ of students stated that learning had increased responsibility, which was marked by:

- Demanding students to create their own learning tools, such as task lists and reminders (94,64\%),

- Learning is not restricted in a narrow problem, but rather broaden their horizon open-endedly in inquiry-based activities $(98,21 \%)$,

- Students are required to design activities that require planning, achievement, and selfassessment (96,43\%),

- Providing opportunities for decision making to control activities, resources used, even class policies $(98,21 \%)$.

\section{B. Discussion}

\section{G-Drive Benefits}

Google Drive and Google Docs can be used for free, built specifically for schools, universities and nonprofit organizations and does not need to download new software or buy hardware (Oishi, 2007). This software, allows users to share and collaborate various Word sheets, presentations and other documents. For teaching purposes, this software can have a number of clear benefits both inside and outside the classroom. Although there is a rather limited function compared to other software, it still allows students to get many benefits. Firth and Mesureur (2010) noted that Google Drive can be used to list names, subject management, assessment, joint work and homework work. 
In the Web 2.0 era, there are several web applications that have been developed to serve every user openly and freely, such as Flickr, Wikis, WordPress, and Google services. All of these web applications provide a friendly interface and powerful functionality. Teachers and students use a lot of web applications in their daily lives. Based on these features, some literature shows that web applications that are well known can become potential new ways to involve participants in meaningful learning activities (Alexander, 2006; Hughes, 2009; Schneckenberg, Ehlers, \&Adelsberger, 2011; Thompson, 2007; Wang, Woo, Quek, Yang, Liu, 2012 in Lin, \&Jou, 2012).

Dohn (2009) argues that teachers and students will be motivated to use applications in education when they have the necessary technical skills. They are only required to apply the application to assist in managing classroom learning activities (Pretlow\&Jayroe, 2010). Previous studies have shown that more web-enhanced learning can outperform traditional lecture formats (Crook \& Harrison, 2008; Hamann\& Wilson, 2003). Effective use of web applications can remove the boundaries between formal and informal learning (Bennett, et.al., 2012 in Lin, \&Jou, 2012).

Google web applications such asGoogle Docs, Google Drive and Google Sites, can be adopted to develop learning environments. Drive, documents and forms can be used to facilitate the interaction of students. Google documents provide web-based document services that allow users to create and edit documents online through a web browser. In addition, users can easily share their documents with others. Google provides an online questionnaire service form that allows users to create an online questionnaire to survey efficiency and effectiveness of learning. With regard to Google sites, this provides an easy way to allow users to create dynamic web pages with teammates as easy as writing documents. This means that every user can use this service without problems even though they do not have web programming skills.

Teachers can ask students to use GoogleDrive to do reflective learning activities, which is to improve their understanding of their own thinking processes (Jou\&Shiau, 2012). Teachers can also use GoogleDrive to view each student's documents, provide comments and suggestions. Furthermore, using Google forms can manage an online questionnaire to monitor the status and performance of students' learning during the learning process. Formative information can be a useful basis for teachers to understand students' minds and adjust learning steps. Last but not least, teachers can direct students to apply Google sites in collaborative team projects.

Learners can create Google documents to record the status and notes of their learning such as using Microsoft Office Word. They can express their opinions and thoughts by replying to the teaching form. In addition, students can present their learning outcomes with colleagues through the use of Google sites. Google Drive and other tools that aim to create educational processes based on interactive methodologies have succeeded in increasing student motivation, as well as teacher enthusiasm that is strongly supported by this new, more collaborative and closed environment.

The convenience of Google Drive and Google Appsin general for Education users makes students sink into a new approach without knowing it. The work becomes much easier and encourages teachers to continue working with new methodologies. Students are satisfied because they can have their own account and can store all the files in the cloud and access them from any device. One researcher stated "the learning capacity is greater because the motivation is greater. That inter-relationship is also enhanced because students help each other and share documents on Google Drive."

The system indeed promotes accessibility; the fact that it is free from incidents, and students do not have to go to certain classrooms to use computers, all in user friendliness. In terms of network advantages, it is very practical to be able to access class material anywhere without having to rely on full of risk shared disks on the school's internal network, with additional benefit of being able to continue working without the necessity of bringing material inflashdrive, thus eliminating the risk of loss or error. Besides having a direct impact on student performance and motivation, the Google Drive has given students better reading comprehension, increased critical abilities, a large capacity to inform themselves, and excellent, high-value digital competencies both in the present and in the future.

\section{Conclusion}

In conlcusion, the Google Drive application provides support for educational organizations in the form of:

1) Providingessential security features specifically designed to keep data safe, protected and controlled.

2) Everything is stored automatically in the cloud, powered by the web; e-mail, documents, calendars, and sites can be accessed and edited on almost all mobile or tablet devices, anytime and anywhere.

3) Fast and easy collaboration; Document-making devices and websites offer editing at all times, controlling in sharing and unlimited compatibility, which is an ideal environment for learning in the $21^{\text {st }}$ century.

4) Helping facilitate academic tasks such as essay writing and class scheduling; a group of students can work together to create a work on Google Drive since they can see and make changes at any time without waiting.

5) Learners, instructors, and administrators at all times have access to the latest software, including its features and renewable security systems.

6) Helping reduce organizational expenses and environmental impacts. The application is 
supported by an efficient Google data center, so no need to waste energy.

The benefits obtained in self-regulated learning through Google Driveare as follows:

1) Making active learning, characterized by providing more learning experience opportunities to achieve goals, using peer teaching techniques to increase participation, learning process has demanded students to motivate challenging work, and build the habit of gaining new knowledge.

2) Making activities more authentic through role playing activities based on real life situations, using real-world resources from open web, and assessment models that develop students' responsibility.

3) Developing students' metacognition through selfevaluation, and self-reflection through activity journals. Students are also able to develop some ways to approach problems and use of technology to facilitate learning access.

4) Fostering intrinsic motivation through learning completeness by accelerating the growth of mindset, designing goals and recording progress in learning independently, conducting cooperative and collaborative activities to achieve common goals.

Increasing students' responsibility through the creation of self-learning tools, broadening horizon through inquirybased insights, designing activities and assessing themselves, and controlling all the use of the learning resources themselves.

\section{References}

Aditomo, A. (2014). Evaluating the validity of an epistemic belief questionnaire: Evidence based on internal structure, content, and response process. ANIMA Indonesian Psychological Journal, 29(3), $155-168$.

Bransford, J. D., Sherwood, R. D., Hasselbring, T. S., Kinzer, C. K., \& Williams, S. M. (1990). Anchored instruction: Why we need it and how technology can help. In D. Nix \& R. J. Spiro (Eds.), Cognition, education, and multimedia: Exploring ideas in high technology (pp. 115-141). Hillsdale, NJ, US: Lawrence Erlbaum Associates, Inc.

Collins, A. (1996). Design issues for learning environments. International perspectives on the design of technology-supported learning environments, 347-361.

Crook, C., \& Harrison, C. (2008). Web 2.0 technologies for learning at key stages 3 and 4: summary report.
Cuban, L., Kirkpatrick, H., \& Peck, C. (2001). High access and low use of technologies in high school classrooms: Explaining an apparent paradox. American educational research journal, 38(4), 813834.

Dohn, N. B. (2009). Web 2.0: Inherent tensions and evident challenges for education. International journal of computer-supported collaborative learning, 4(3), 343-363.

Duffy, T. M., \& Knuth, R. A. (1990). Hypermedia and instruction: Where is the match?. In Designing hypermedia for learning (pp. 199-225). Springer, Berlin, Heidelberg.

Firth, M., \& Mesureur, G. (2010). Innovative uses for Google Docs in a university.

Gaitero, O.G., Román, O.C,. and García, J.J.R (2015:49), A New Theoretical Construct in the Concept of Self-Regulated Learning, International Journal of Educational Excellence,(2016) Vol. 2, No. 1, 4961.

Hamann, K., \& Wilson, B. M. (2003). Beyond search engines: Enhancing active learning using the internet. Politics \& Policy, 31(3), 533-553.

Harris, S. (2002). Innovative pedagogical practices using ICT in schools in England. Journal of Computer Assisted Learning, 18(4), 449-458.

Jonassen, D. H., Peck, K. L., \& Wilson, B. G. (1999). Learning with technology: A constructivist perspective.

Jou, M., \&Shiau, J. K. (2012). The Development of a WebBased Self-Reflective Learning System for Technological Education. Turkish Online Journal of Educational Technology-TOJET, 11(1), 165171.

Kennewell, S., Tanner, H., \& Parkinson, J. (2000). A model for the study and design of teaching situations with ICT. In Communications and Networking in Education (pp. 129-138). Springer, Boston, MA.

Kizilcec, R.F., Sanagustín, M.P., \& Maldonado, J.J., 2016, Self-regulated learning strategies predict learner behaviour and goal attainment in Massive Open Online Courses, Journal Computers \& Education, Elsevier Ltd. 
Korpershoek, H, et.al. (2016), A Meta-Analysis of the Effects of Classroom Management Strategies and Classroom Management Programs on Students' Academic, Behavioral, Emotional, and Motivational Outcome, Review of Educational Research September 2016, Vol. 86, No. 3, pp. 643680,University of Groningen.

Lin, Y.T., \&Jou, M., 2012, A Web Application Supported Learning Environment for Enhancing Classroom Teaching and Learning Experiences, International Educational Technology Conference, IETC2012, Published by Elsevier Ltd. Selection and/or peerreview under responsibility of The Association Science Education.

Mitchell, B.S., Hirn, R.G. and Lewis, T.J. (2017), Enhancing Effective Classroom Management in Schools: Structures for Changing Teacher Behaviour, Teacher Education and Special Education 2017, Vol. 40(2) 140-153, SAGE Publishing.

Mudjia Rahardjo, 2017, Studi Kasus Dalam Penelitian Kualitatif: Konsep dan Prosedurnya, Malang: Program Pascasarjana, Universitas Islam Negeri Maulana Malik Ibrahim.

Oishi, L. (2007). Working Together: Google Apps Goes to School. Technology \& Learning, 27(9), 46.

Pretlow, C., \& Jayroe, T. (2010). Training in the Clouds. Computers in Libraries, 30(4), 18-23.

Scheerens, J. (2004). The evaluation culture. Studies in Educational Evaluation, 30(2), 105-124.

Schneckenberg, D., Ehlers, U., \&Adelsberger, H. (2011). Web 2.0 and competence-oriented design of learning-Potentials and implications for higher education. British Journal of Educational Technology, 42(5), 747-762.

Smeets, E. (2005). Does ICT contribute to powerful learning environments in primary education? Computers \& Education, 44(3), 343-355.

Wang, C.S., 2010, Students' Characteristics, SelfRegulated Learning, Technology Self-Efficacy, and Course Outcomes in Web-Based Courses, Dissertation, Alabama: Auburn University.

Young, J. (2002). The 24-hour professor. The Chronicle of Higher Education, 48(38), 31-33. 